\title{
Sobre a Ocorrência de Sítios dos Amoladores - Polidores Fixos no Litoral da Bahia
}

\author{
Cristiana de Cerqueira Silva-Santana* \\ Hélio Augusto de Santana** \\ Noelia Souza Vieira* \\ Fernanda da Silva Lima*
}

\section{Introdução}

moladores-polidores fixos, termo disseminado por Gaspar \& Tenório (1990), constituem sítios arqueológicos pré-coloniais correspondentes a suportes rochosos utilizados como superfícies para a abrasão e o polimento durante os processos de confecção e/ou acabamento de artefatos líticos, bem como para aguçar ou reparar gumes. Tiburtius \& Bigarella (1953) conferem a esses sítios a potencialidade adicional de polimento de artefatos em ossos e vegetais.

Esse tipo de sítio, também designado de pedras de amolar, oficinas líticas de polimento, dentre outras denominações, geralmente é encontrado em ilhas costeiras e às margens de desembocadura de riachos, estando bem caracterizado nos estados de Santa Catarina (Tiburtius \& Bigarella 1953; Rohr 1960; Beck 1971; Rüthschilling \& Schmitz 1990; Branchelli 2008; Rodrigues-Carvalho et al 2011) e do Rio de Janeiro (Gaspar \& Tenório 1990; Tenório 1999, 2003a, 2003b; Gaspar et al 2004; Oliveira \& Funari 2005; Tenório, Pinto, Afonso 2008).

Embora recorrentes no trecho litorâneo sul/sudeste, alguns desses sítios foram também localizados em outras regiões do Brasil, bem como em trechos mais interioranos, borde-

(*) Laboratório de Arqueologia e Paleontologia da Universidade do Estado da Bahia - UNEB. <ccsilva@uneb.br>, <cristiana_santana@hotmail.com >; <noehliavieira@gmail. com>; <fefeslima10@hotmail.com>

$\left.{ }^{(* *}\right)$ Pesquisador Consultarq <helioaugusto@hotmail.com>. jando riachos e alto curso de rios conforme estudos de Chmyz \& Sauner (1971), Ribeiro (1999), Herberts et al. (2006), Rocha et al (2009), FAPERJ (2012), Garcia \& Garcia (2012).

Para o estado da Bahia há o registro de apenas um sítio amolador-polidor fixo localizado dentro da Baía de Todos os Santos, na ilha de Cajaíba, município de São Francisco do Conde (Calderón 1974). Segundo Calderón, trata-se de sinais de amolar em formato de linhas acanaladas paralelas ou cruzadas, situados à margem da praia e nas proximidades do sambaqui Cajaíba, ao qual Calderón correlacionou às pedras de amolar, a partir da ocorrência de machados polidos no sambaqui.

Durante pesquisas realizadas no litoral da Bahia foram evidenciadas duas novas áreas contendo amoladores-polidores fixos. Uma dessas corresponde ao sítio Angolá, no município de Maragogipe, Baía de Todos os Santos (BTS); o outro, denominado sítio Pedra do Índio, localiza-se no município de Esplanada, litoral norte do estado.

\section{Considerações sobre os sítios Angolá e Pedra do Índio}

O sítio Angolá é caracterizado por um afloramento rochoso localizado em área urbana, no bairro de mesmo nome, na periferia da sede municipal de Maragogipe, às margens do manguezal. Os amoladores encontram-se na calçada em frente a uma construção residencial, estando parcialmente recobertos por esta 
(Fig. 1). O afloramento revela um conjunto de sulcos (frisos) paralelos e perpendiculares, bem como bacias ovaladas e pequenas cavidades circulares, sendo também observados conjuntos de frisos e de pequenas bacias (Fig. 1). Os sulcos são rasos, com aproximadamente $0,6 \mathrm{~cm}$ de profundidade e pouco espessos, variando entre 0,5 e $1,0 \mathrm{~cm}$; apenas um sulco profundo e de maior espessura em torno de 2,0 cm é ob- servado. Os círculos e bacias são rasos e variam diametricamente entre 1,0 e $30 \mathrm{~cm}$. É possível que o sítio seja maior que o observado e que existam marcas de polir e amolar sob a residência, o calçamento e soterrados por sedimento da rua.

O sítio Pedra do Índio está localizado a aproximadamente $8 \mathrm{~km}$ da atual linha de costa, às margens de um riacho que integra a porção
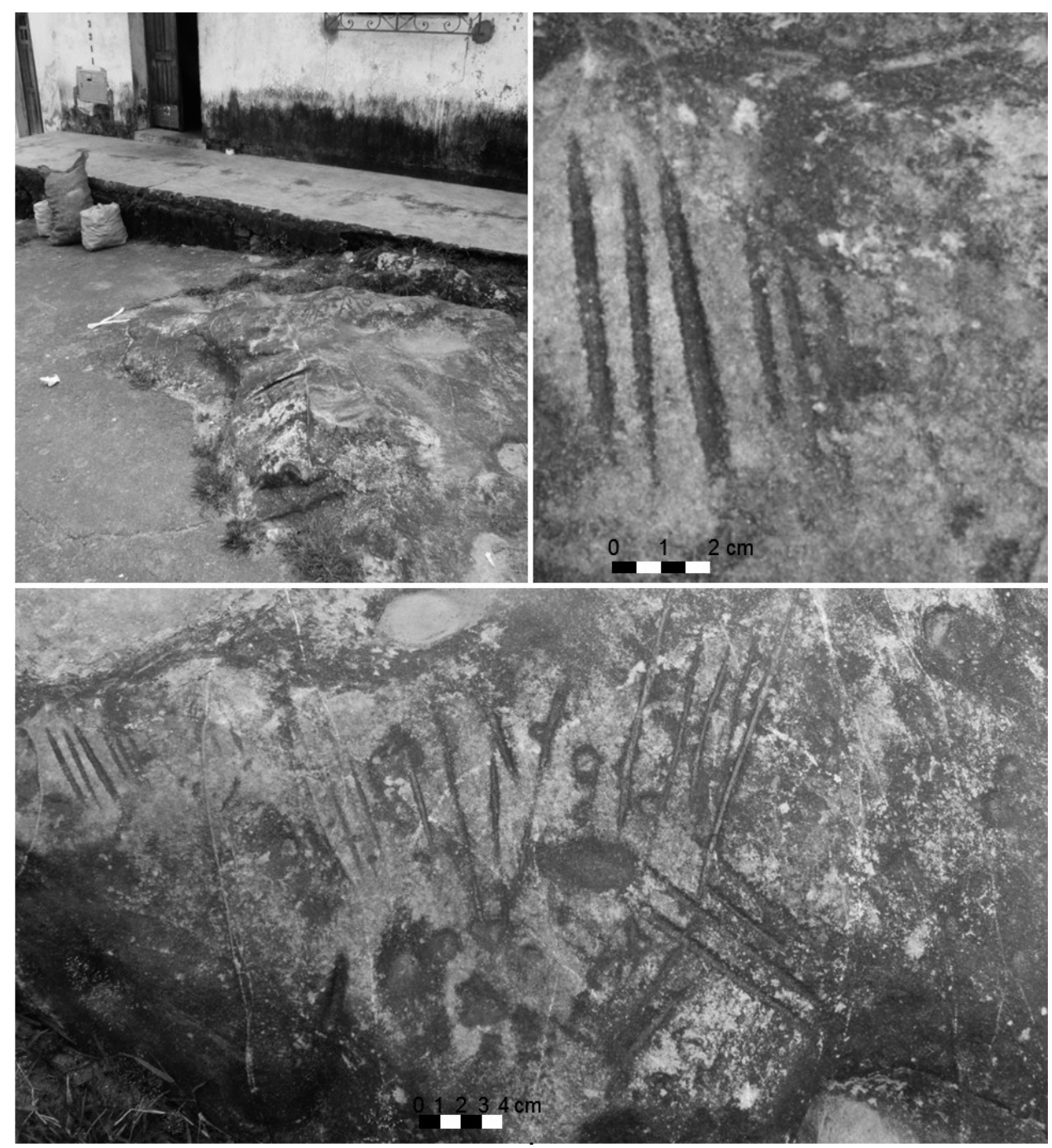

Fig. 1. Vista do sítio Angolá (à esquerda, acima); em detalhe amoladores-polidores. 
final do rio Subaúma, município de Esplanada, litoral norte do estado.

A Pedra do Índio consiste de vários afloramentos rochosos que exibem admirável conjunto de amoladores-polidores caracterizados por frisos paralelos e, por vezes, perpendiculares, estreitos (entre de 0,4 e 0,8 cm) e pouco profundos (entre 0,5 e 1,0 cm); uma única bacia ovalada é observada (Fig. 2). A área dos blocos rochosos apresenta depósito sedimentar que encobre provavelmente muitos outros amoladores.

Ainda que alguns amoladores-polidores fixos sejam encontrados fora das áreas costeiras, a maioria das evidências localiza-se em regiões litorâneas e apresenta correlação espacial direta com sambaquis.
Tenório (2003a) salienta que em Santa Catarina a grande maioria dos sítios amoladores-polidores fixos está associada a sambaquis e acampamentos. Para o estado, Tenório informa que $82,3 \%$ dos sítios dos amoladores-polidores fixos estão integrados a áreas de influência das culturas sambaquieiras, sejam diretamente relacionados aos sítios sambaquis $(67,6 \%)$ ou a acampamentos articulados a estes (14,7\%). Essa correlação também foi observada por Tenório (2003b) para o estado do Rio de Janeiro.

Durante as atividades de campo desta pesquisa não foram localizados sambaquis na área do sítio Angolá; todavia, o mesmo está situado na BTS, região com vários registros de sambaquis (Calderón 1964, 1974, Silva-Santana et al 2013), existindo inclusive a presença de um

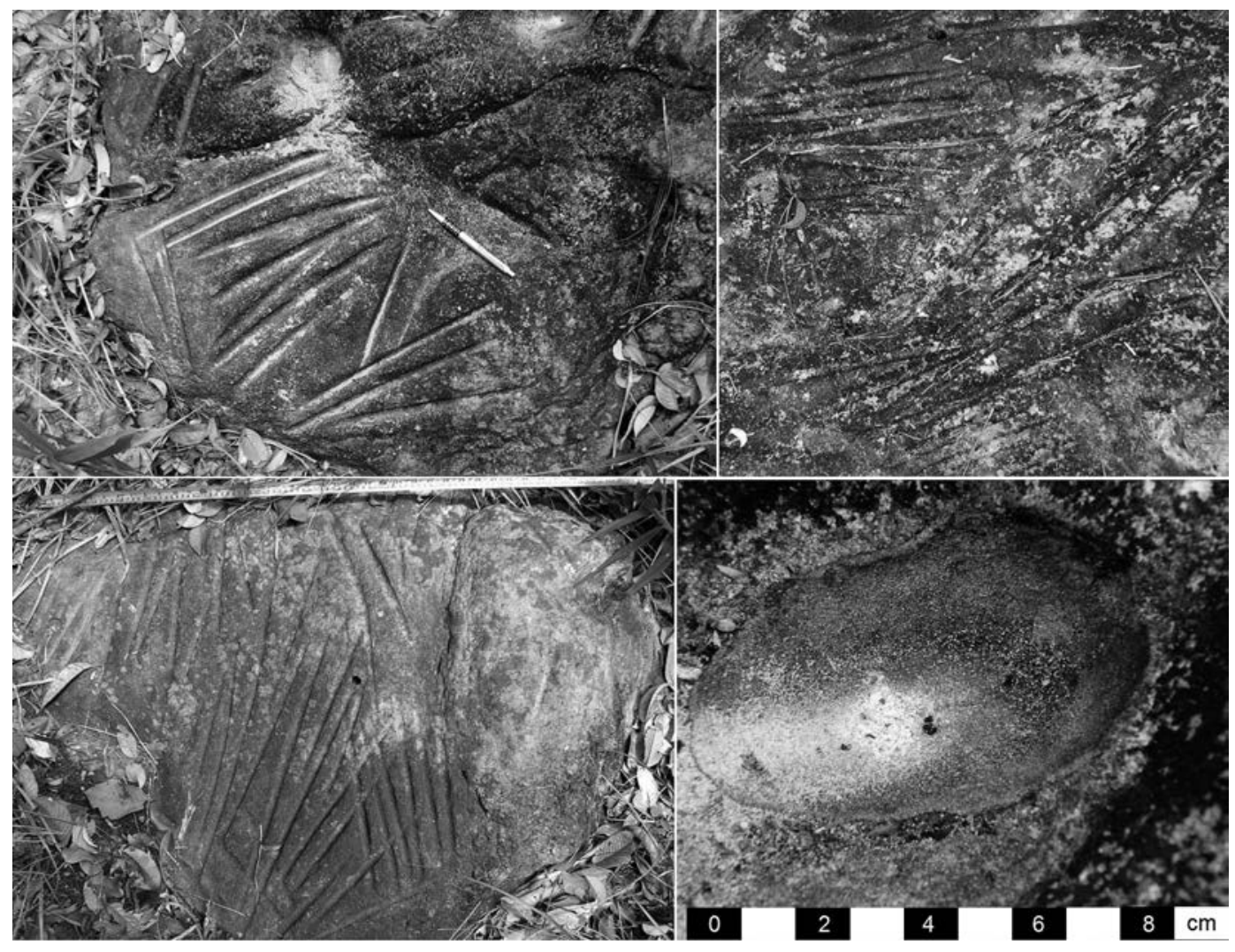

Fig. 2. Detalhe dos frisos de amolar e bacia de polimento (à direita, abaixo) do sítio Pedra do Índio, Esplanada, Bahia. 
sítio amolador-polidor fixo associado ao sambaqui Cajaíba na região, conforme mencionado por Calderón (1974). Igualmente para o sítio Pedra do Índio não se constatou sambaquis nas proximidades; contudo, estudos realizados no município vizinho (Conde) identificaram cinco sambaquis, e em três desses ocorreram artefatos líticos polidos (Silva 2000, Silva-Santana 2007). Merece ainda a observação de que embora o sítio Pedra do Índio se situe atualmente distante cerca de $8 \mathrm{~km}$ da atual linha de costa, a região de inserção do mesmo encontrava-se mais próxima do mar (aproximadamente $2,5 \mathrm{~km}$ ) durante o evento marinho da Última Transgressão Holocênica, conforme mapas da Geologia evolutiva em Silva (2000). Nesse sentido, considera-se plausível a hipótese de existência de sambaquis nas circunvizinhanças de ambos os sítios e que tais amoladores estejam relacionados à produção de polidos para os sambaquis da BTS e do litoral norte da Bahia.

\section{Agradecimentos}

Ao CNPq e à FAPESB pelo apoio ao "Projeto Sambaquis do Recôncavo Baiano" (Universal, Coordenadora Cristiana Santana), viabilizador da pesquisa.

\section{Referências bibliográficas}

BECK, A.

1971 Os sambaquis do litoral de Laguna - SC. In: Duarte, P. (Ed.). O Homem Antigo na América. São Paulo, Instituto de Pré-História, USP: 69-76.

BRANCHELLI, F. A.

2008 Da Pré-História à História: arqueologia da Ponta do Porto Novo, Praia do Rosa - SC. In: Anais do IX Encontro Estadual de História da Associação Nacional de História, CALDERÓN, V. Rio Grande do Sul: 1-14.

1964 O sambaqui da Pedra Oca. Relatório de uma Pesquisa, 2. Universidade Federal da

CALDERÓN, V. Bahia, Instituto de Ciências Sociais, 88p.

1974 Contribuição para o conhecimento da arqueologia do recôncavo e do sul da Bahia. Boletim do Museu Paraense Emílio Goeldi, 26: 141-155.

CHMYZ, I \& SAUNER, Z. C.

1971 Nota prévia sobre as pesquisas arqueológicas no Vale do Rio Piquiri. Dédalo. São Paulo, 3:7-36.

2012 Pesquisadores descobrem sítio arqueológico no interior do estado. Fundação Carlos Chagas Filho de Amparo à Pesquisa do Estado do Rio de Janeiro. Disponível em: http://www.faperj.br/boletim_interna. phtml?obj_id=8290.

GARCIA, M. C. O.; GARCIA, J. da S.

2012 Pedras que guardam segredos: catalogação de sítios arqueológicos na região centro-leste de Rondônia. Revista Veredas Amazônicas, 1 (II): 33-66.

GASPAR, M. D.; TENÓRIO, M. C.

1990 Amoladores e polidores fixos do litoral brasileiro. Revista do CEPA, 17 (20): 181190.

GASPAR M. D., TENÓRIO M. C., BUARQUE A., BARBOSA-GUIMARÃES M., OLIVEIRA J. C. \& SCHEEL-YBERT R.

2004 Projeto de Investigação: O Aproveitamento Ambiental das Populações Pré-Históricas do Rio de Janeiro. Arquivos do Museu Nacional, 62 (2): 103-129.

HERBERTS, A. N.; LAVINA, R.; COMERLATO, F.; COSTA, C.

2006 Oficinas líticas de polimento no interior de Santa Catarina. In: Anais do V Encontro do Núcleo Regional Sul da Sociedade de Arqueologia Brasileira: 1-4.

OLIVEIRA, N. V. DE; FUNARI, P. P. A.

2005 Camarqueologia em Angra dos Reis, Rio de Janeiro/RJ. Revista Eletrônica Patrimônio: Lazer $\mathcal{E}$ Turismo. UniSantos: 1-37. 
RIBEIRO, P. M.

1999 Os mais antigos caçadores do sul do Brasil. In: TENÓRIO, M. C. (org.). Pré-História da Terra Brasilis. EDUFRJ: 136-148.

ROCHA, G. DA R.; OLIVEIRA, V. E. H.; TIZUKA, M. M.; KIPNIS, R.; NEVES, E. G.

2009 Os amoladores-polidores sobre rochas no alto rio Madeira. In: Anais da $61^{a}$ Reunião da SBPC: $1-2$.

RODRIGUES-CARVALHO, C.; SCHEEL-YBERT, R.; GASPAR, M.; BIANCHINI, G. F.; KLOKLER, D. M.; ANDRADE, M. N. DE; BORGES, D. DE S.

2011 Cabeçuda-II: um conjunto de amoladores-polidores evidenciado em Laguna, SC.

Revista do Museu de Arqueologia e Etnologia, São Paulo, 21: 401-405.

ROHR, J. A.

1960 Pesquisas paleoetnográficas na Ilha de Santa Catarina e notícias prévias sobre sambaquis da Ilha de São Francisco do Sul, III. Pesquisas (Série Antropologia), São Leopoldo, 12: 1-18.

RÜTHSCHILLING, A. L.; SCHMITZ. P. I.

1990 O sambaqui da praia das Laranjeiras, Balneário de Camboriú. Revista do CEPA, 17 (20): 191-203.

SILVA, C. DE C.

2000 Herança Geológica como ferramenta para a prospecção de sambaquis no Litoral Norte do Estado da Bahia: o exemplo do sambaqui Ilha das Ostras. 127f. Dissertação de Mestrado. Salvador, Universidade Federal da Bahia.
SILVA-SANTANA, C. DE C.

2007 Sambaquis Perilagunares da Costa do Conde, Bahia. Tese de Doutorado. Salvador, Universidade Federal da Bahia.

SILVA-SANTANA, C. DE C.; SILVA, A. C. G DA; LIMA, F. DA S.; VIEIRA, N. S.; SANTANA, J. A. B.

2013 Sambaqui do Paty ou um sítio multicomponencial para a coleta de mariscos? Tarairiú, 6: 98-110.

TENÓRIO, M. C.

1999 Os fabricantes de machado da Ilha Grande. In: Tenório, M.C. (Ed.) Pré-história da Terra Brasilis. Rio de Janeiro, EDUFRJ: 233-246.

TENÓRIO, M. C.

2003a Os amoladores-polidores fixos. Revista de Arqueologia, 16: 87-108.

TENÓRIO, M. C.

2003b O lugar dos Aventureiros: identidade, dinâmica de ocupação e sistema de trocas no litoral do Rio de Janeiro há 3500 anos antes do presente. Tese de Doutorado. Porto Alegre, Pontífica Universidade Católica.

TENÓRIO M. C., PINTO D. C. \& AFONSO M. C. 2008 Dinâmica de Ocupação, Contatos e Trocas no Litoral no Rio de Janeiro. Arquivos do Museu Nacional, Rio de Janeiro, 66 (2): 311-321.

TIBURTIUS, G.; BIGARELLA, I.

1953 Nota sobre os anzóis de osso da jazida paleoetnográfica de Itacoara, Santa Catarina. Revista do Museu Paulista, 7: 381-387. 